\title{
Claude Lévi-Strauss por Françoise Héritier
}

FRANÇOISE HÉRITIER (ENTREVISTA)

A

ANTROPÓloga francesa Françoise Héritier foi entrevistada por Marc Kirsch, diretor editorial da La Lettre du Collège de France, para o número especial da publicação comemorativo do centésimo aniversário de Claude Lévi-Strauss.

Françoise Héritier foi sucessora de Claude Lévi-Strauss no Collège de France (Cátedra de Estudos Comparativos das Sociedades Africanas de 1982 a 1998). Hoje é professora emérita. É autora de L'exercice, De la parenté inceste, L'Masculin/féminin: la pensée de la différence, e De la violence.

La Lettre - Ao entrar no Collège de France no momento em que Claude Lévi-Strauss saía, a senhora de certo modo o sucedeu. Como se deu essa sucessão? Que relações mantinha com ele?

Françoise Héritier - Convém falar mais de uma sucessão intelectual, pois, por um lado, do ponto de vista institucional, as cadeiras do Collège de France não têm sucessão, e, por outro, quando fui eleita para o Collège em 1981, LéviStrauss ainda era o titular da sua.

A passagem se deu bem, primeiro porque, de certo modo, o próprio LéviStrauss havia me escolhido: entre os pretendentes possíveis, eu era certamente quem melhor correspondia às suas preocupações teóricas, sobretudo no domínio do parentesco, que fora o seu grande tema de pesquisa. Além disso, tenho muito respeito e admiração pela obra, e, pelo homem, uma grande afeição e uma amizade que nunca variaram desde que o conheço.

Isso não quer dizer que mantivéssemos relações privilegiadas ou uma comunicação mais íntima: Claude Lévi-Strauss é uma pessoa reservada e mesmo bastante distante, austera - pelo menos é a imagem que passa e à qual correspondeu cada vez mais com o avanço da idade. Sei que ele apreciava alguns dos meus trabalhos, mas não estou certa de que aprovasse do mesmo modo alguns dos mais recentes, em particular sobre a relação de gênero e a relação de sexo.

Lévi-Strauss sabia que existe uma desigualdade nas relações entre os sexos e a analisa na relação irmão/irmã, mas não fez dela um motor essencial dos modelos que estabeleceu para compreender o fato social. Ele mostrou como a criação do social se originou da necessidade, para os grupos humanos, de sobreviver, e assim de encontrar modos de coexistência pacífica em longo prazo, o que 
é a condição essencial dos acordos de troca matrimonial com os outros grupos. O estabelecimento dessas trocas levou à proibição do incesto, que exige para um homem não mais tomar suas esposas no próprio grupo, mas trocar as irmãs ou as filhas por mulheres provenientes de outros grupos. Proibição do incesto e exogamia subsequente induzem outras obrigações. É necessário, em particular, estabilizar as trocas, o que impõe a união institucional entre grupos - que chamamos tradicionalmente o casamento - e a repartição sexual das tarefas entre os cônjuges. Esses quatro elementos representam o modelo lévi-straussiano da criação do vínculo social. Para Lévi-Strauss, essa repartição sexual das tarefas, no interior do casamento que une grupos, é a maneira de consolidar a relação de dependência entre um homem e uma mulher unidos por esses laços em razão da vontade do seu grupo. Ao fazê-los dependentes um do outro na materialidade da vida doméstica e pela repartição sexual das tarefas, torna-se duradouro o casamento entre grupos, que é a marca oficial da exogamia, a qual decorre da proibição do incesto e da absoluta necessidade de estabelecer a paz.

Esse modelo possui grande verossimilhança em relação à multiplicidade das sociedades humanas. Ele recebeu, porém, objeções: por exemplo, de que o casamento não é uma consequência absoluta da exogamia, de que a troca talvez não seja a base do social, mas os exemplos fornecidos em apoio a essas críticas nunca foram bastante convincentes. Penso numa tribo na China, sobre a qual o próprio Lévi-Strauss (2000) mostrou, num número especial de L’Homme dedicado às questões do parentesco, que ela representa apenas um dos pontos extremos de um vetor que leva da matrilinearidade mais extrema à patrilinearidade mais extrema. Teoricamente, ali o casamento não existe e a paternidade não é reconhecida. Mas isso não quer dizer que não haja união estável entre um homem e uma mulher, nem mesmo paternidade sensível e ostensiva entre um homem e os filhos. Sobre a população em questão, os $\mathrm{Na}$, descobri recentemente uma observação interessante num livro que me enviaram. Não é um livro científico, mas a autobiografia de uma cantora de ópera originária dessa etnia $\mathrm{Na}$. Ela relata sua infância e juventude nessa sociedade de mulheres, da qual os homens partiam para fazer comércio e viagens de longo curso, voltando de tempo em tempo. Conta sua alegria de correr ao encontro do "pai" quando ele retornava de viagem e a felicidade compartilhada do reencontro. É evidente que ela sabia muito bem que era seu pai, mesmo não tendo havido cerimônia "oficial" durante a qual uma mulher teria sido dada em casamento a um homem, e mesmo não havendo residência comum permanente. A mãe mostrava os mesmos sentimentos. Tratava-se de ligações menos formais, mas havia algo que correspondia de fato ao resultado da união entre um homem e uma mulher com sua descendência.

Apesar disso, as explicações de Lévi-Strauss sobre a repartição sexual das tarefas não me pareciam inteiramente satisfatórias. Aos poucos fui vendo que faltava nessa argumentação uma peça fundamental. Se de fato os grupos eram obrigados a se entender para sobreviver e a contrair alianças matrimoniais em vez de se matar entre si, e se isso se traduz em toda parte pelo fato de serem os 
homens que trocam mulheres e não o inverso, é que já havia, desde o início, uma desigualdade e um direito reconhecido a esses pais e a esses irmãos de disporem do corpo de suas filhas e de suas irmãs. Vejo aí o quarto pilar das sociedades humanas - sendo os outros três, no esquema de Lévi-Strauss, a proibição do incesto, a exogamia e a instauração de uma lei oficial que une entre si as famílias e as linhagens, e a repartição sexual das tarefas. Esse quarto pilar está na origem da repartição sexual das tarefas e dá à "valência diferencial dos sexos" uma importância bem maior que a que Lévi-Strauss lhe dava. De minha parte, aliás, dou à valência diferencial dos sexos o papel decisivo. Sobre esse ponto é provável que estivéssemos em desacordo. Assim, não me proíbo de ter um olhar crítico, mas construtivo, sobre a obra de Lévi-Strauss. Considero sua obra essencial e nela me apoiei para o meu próprio trabalho. Pode-se debater ao infinito sobre o caráter estruturalista, positivista ou humanista da obra, mas não se pode negar a fecundidade desse pensamento.

La Lettre - Essa diferença de sensibilidade às questões ligadas às diferenças dos sexos se deve a um efeito de geração?

$F H$ - Certamente. Lévi-Strauss é um homem do seu tempo. De uma certa maneira, ele considera que essa repartição das tarefas é boa e que é normal, já que as mulheres procriam, que elas devam se ocupar dos filhos, do lar etc. Isso não coloca problema para ele. Não se trata de cegueira - se há um homem de quem não se pode suspeitar de cegueira, é ele. Trata-se antes de ratificar uma situação que ele considera como natural. Sobre esse ponto, ele não foi impelido intelectualmente a levar adiante a análise como eu fiz. Pode-se dizer que é porque sou mulher, mas acho mais razoável pensar que é porque sou de uma outra época e sensível a situações percebidas mais recentemente. Além disso, eu tinha necessidade de uma coerência global e não estava satisfeita com a ideia da repartição sexual das tarefas como complemento necessário para tornar os esposos dependentes um do outro, obrigando assim os casais a ficar juntos e a não confundir as linhagens que haviam organizado a união sobre a qual repousava a paz entre as tribos. Resolvi então examinar um pouco mais longe.

\section{La Lettre - Que tipo de homem é Claude Lévi-Strauss?}

$F \boldsymbol{H}$ - Em primeiro lugar, um homem extremamente cortês. Misantropo em geral, sem dúvida, e benevolente em suas relações com as pessoas, muito sensível, apesar da imagem de homem frio e distante que geralmente lhe atribuem. Na sua antiga sala do Collège de France, na Place Marcelin-Berthelot, ele tinha uma maneira muito particular de acolher os visitantes e de conduzi-los pela mão até as poltronas de couro bastante fundas, das quais se tinha a maior dificuldade de sair. É também um homem que conserva sempre uma certa reserva. No Laboratório de Antropologia Social, era mais fácil comunicar-se com ele durante um seminário do que em conversas particulares. Ele preferia exprimir-se em público e esperava de seus pesquisadores que viessem expor seus trabalhos nos seminários. Ali escutava com atenção e fazia a seguir uma síntese do que ouvira e colocava questões muito pertinentes. Seus comentários eram sempre esclarecedores. 
Mas ele é, sobretudo, um homem da escrita. Quando lhe escrevíamos para lhe falar de um problema, de uma dificuldade, de uma curiosidade num trabalho de campo, ele sempre respondia por cartas manuscritas bastante longas que retomavam a questão colocada ou a contornavam, mas de maneira construtiva. Lembro uma carta que ele me escreveu durante uma de minhas primeiras missões na África, entre os Samo. Eu lhe falava do meu espanto de ter encontrado uma sociedade em que cada aldeia era dividida em duas metades: metade da terra e metade da chuva. Lévi-Strauss havia teorizado as sociedades em metades, encontradas sobretudo na América Latina, e lhe perguntei se ele pensava que podia se tratar do mesmo tipo de organização. Era o que ele suspeitava - com razão. Mas sua resposta continha uma observação que me ficou na memória. Ele dizia em suma: "Minha cara Françoise, o que convém fazer no trabalho de campo não é tentar reencontrar o que lhe ensinaram ou o que você pode ter lido, mas se deixar levar pelo que se expõe diante dos seus olhos". É preciso primeiro observar, para depois interpretar. É preciso deixar-se envolver pelo trabalho de campo. Eram umas poucas palavras, mas fundamentais. Retomei a observação para mim mesma e com ela beneficiei meus próprios alunos.

La Lettre - É bastante impressionante para alguém de quem foi dito que não era um grande pesquisador de campo. Ele escreve, em De perto e de longe, que fez mais do que pensam os seus criticos, mas provavelmente menos do que poderia ter feito, simplesmente porque não tinha muito gosto para isso e se considerava mais como um homem de gabinete.

$F H$ - É a razão pela qual ele se lançou em projetos - As estruturas elementares do parentesco ou as Mitológicas - que requeriam antes trabalhos de biblioteca. Isso não quer dizer que não gostasse dos índios com os quais partilhou a vida. Em Tristes trópicos, além do desencantamento e do olhar terrível e premonitório que lança sobre o mundo contemporâneo, encontramos também algo que não é nem enternecimento, nem compaixão, mas se assemelha a uma espécie de comunhão imediata, de empatia, com o que há de essencial na espécie humana. Gosto muito de um relato em que ele acompanha um pequeno grupo de Nambiquara na floresta. É noite, faz frio, chove. Eles estão nus e se comprimem ao redor do fogo, tendo por única proteção um abrigo de ramagens e folhas, e em relação a esses pobres homens que estão ali, amontoados uns contra os outros, há uma frase maravilhosa que diz que esse pequeno grupo encarna a forma mais tocante que ele jamais viu da fragilidade humana e da afeição que pode unir os membros de uma sociedade.

La Lettre - Há um grande pudor na sua expressão de amor à humanidade ou, mais exatamente, aos humanos, que é talvez a face oculta da sua misantropia.

$F H$ - A misantropia tem por objeto a espécie humana e sobretudo o lado destruidor de nossas civilizações, ela não visa aos indivíduos.

La Lettre - É o que se percebe nas fotografias. Com frequência ele aparece em momentos de alegria, de frescor, de graça. Tem-se a impressão de que elas falam 
imediatamente, embora Lévi-Strauss pense que, em realidade, cada um vê nelas o que quer ver. Ele desconfia do uso que se faz da fotografia.

$F H$ - É preciso mencionar também seu gosto estético. Há alguns anos foi publicado um livro de fotografias tiradas por Luiz de Castro Faria (2001), um dos acompanhantes brasileiros de Lévi-Strauss em sua expedição de 1938 à Serra do Norte. O livro apresenta, como indica o título, Um outro olhar. Comparando suas fotos com as de Lévi-Strauss, temos a impressão de que este, ao fotografar a mesma cena, tendia muitas vezes a evacuar do campo - pelo enquadramento ou depois, ao revelar as fotos - o que podia parecer feio, o que podia evocar o mundo contemporâneo e a invasão, mesmo na floresta amazônica, dos detritos do mundo industrial. Não era para camuflar a realidade, que ele conhecia muito bem, mas provavelmente por preocupação estética. Ele queria que suas fotos fossem belas e assim homenageassem os seus temas.

La Lettre - Ele se interessou muito pela estética do corpo, por tatuagens e pinturas corporais.

$F H$ - Ele faz um inventário delas, com aquele interesse estético que sempre teve. A via das máscaras mostra o mesmo interesse, embora se trate de uma análise estrutural. Lévi-Strauss é muito sensível à beleza dos objetos, tem um gosto pelas decorações, por tatuagens, pinturas, máscaras etc. Ele disse que na juventude pensou em ser cenógrafo. Trouxe de suas missões objetos magníficos que podem ser vistos no Museu do Quai Branly. É um encontro entre seu gosto pessoal e a paixão dos índios pela estética - uma estética barroca diferente da nossa, que possui um requinte cambiante, com enfeites de cabeça, mantos de plumas, cestos, pinturas corporais e muitos outros objetos notáveis. Esse cuidado decorativo lhe pareceu primordial, talvez mais essencial do que saber como eles viam a organização e o funcionamento do corpo humano ou as disfunções da doença.

É também uma maneira de homenagear esses povos, de obrigar o Ocidente a compreender que esses homens, que vivem em universos desprovidos de toda técnica, tidos por atrasados, incultos e mesmo ferozes e sanguinários, atingiram um refinamento em suas práticas corporais que em nada fica abaixo do de nossos enfeites.

La Lettre - Ele conseguiu modificar essa condição do selvagem que é visto com curiosidade e desdém?

$F H$ - Nos círculos intelectuais, sim. Fora deles, não penso que tenha atingido um público bastante numeroso para influir sobre as representações populares de nossa época, nas quais se continua amplamente a considerar que os povos com costumes diferentes dos do mundo ocidental moderno são selvagens. Desse ponto de vista, todos compartilhamos essa constatação de um fracasso relativo, pois não conseguimos fazer entender, mesmo a nossos governantes, essas verdades simples: que se trata de pessoas humanas com um funcionamento intelectual e afetivo idêntico ao nosso, que merecem tanto respeito quanto o homem "civilizado" com suas roupas, atitudes, carros e cigarros. 
La Lettre - Ele foi acusado às vezes de anti-humanismo. Uma entrevista na televisão suiça TSR ${ }^{3}$ oferece um bom resumo da ambivalência aparente que pode ter motivado essas criticas. Ao falar da etnologia, ele declara em síntese: "Se não fosse ofender a dignidade do homem, eu compararia de bom grado os nossos estudos nesse dominio aos do especialista em moluscos e mariscos. Nos mariscos há duas coisas, um animal informe e viscoso que secreta um objeto admirável por suas proporções matemáticas, sua dureza, sua estabilidade, suas cores, e que é a própria concha. As instituições humanas, as crenças e os ritos são bem mais fugazes que a concha dos moluscos, mas possuem um rigor comparável. O etnólogo, diferentemente talvez do psicólogo ou do sociólogo, se interessa menos pela lesma e mais pela concha”. Essas frases poderiam dar margem a acusações de anti-humanismo, mas Lévi-Strauss acrescenta em seguida uma definição da antropologia que faz dela a continuação do grande impulso do humanismo ocidental, encarregado de completar o quadro da totalidade da experiência humana no espaço e no tempo. "Foi no Renascimento", diz ele, "que os homens aprenderam pela primeira vez a refletir sobre o homem a partir da experiência de sociedades muito diferentes tanto no tempo quanto no espaço. As sociedades primeiro estudadas foram apenas as da Antiguidade clássica. Aos poucos o horizonte se ampliou até inlcuir a Índia e a China, e a etnografia não faz senão levar até seu último estágio essa integração da totalidade da experiência humana na reflexão humanista”. Lévi-Strauss liga, num empreendimento humanista comum, a exploração do passado pela bistória e a exploração contemporánea da diversidade humana pela antropologia. Por um lado, portanto, o antropólogoentomologista, por outro, o humanista: trata-se de duas atitudes contraditórias?

$\boldsymbol{F H}$ - Elas não são contraditórias. Lévi-Strauss foi muito sensível a algumas críticas que ele recusa dizendo que a maior parte dos que o criticam o leram mal. E é verdade que, numa obra tão rica, seja inevitável que os pontos de vista e as formulações evoluam, que haja discordâncias entre os textos de juventude e da maturidade. Criticaram-no de ser abstrato, anti-humanista, de ter uma visão totalmente desligada do real e de conservar apenas a estrutura das coisas. Voltaram o estruturalismo contra ele como uma forma de acusação. Ele se defendeu explicando que se tratava de um instrumento, de um procedimento para melhor compreender o mundo. Utilizou metáforas, como a do microscópio. Há diferentes métodos, diferentes níveis para apreciar o real. A água, por exemplo: pode-se vê-la como uma gota que cai de uma torneira. Mas, vista ao microscópio, pode-se chegar até o nível da estrutura molecular - e isso é o trabalho científico. É a mesma água, mas não a vemos mais do mesmo modo. A metáfora serve para fazer compreender que pode haver diferentes níveis de olhar.

Da mesma forma, o molusco e sua concha têm um papel metafórico. O molusco produz a concha e, ao fazê-lo, cria um objeto fascinante por suas propriedades matemáticas e físicas. Numa espécie dada, identificam-se constantes notáveis. Lévi-Strauss quer mostrar que nas ciências humanas também se podem encontrar constantes - leis ou invariantes - que nos permitam fazer comparações como entre as conchas de diferentes moluscos - caracol ou ostra - e conhecer 
Lévi-Strauss em ação: fotografa o indio durante a Expedição à Serra do Norte.

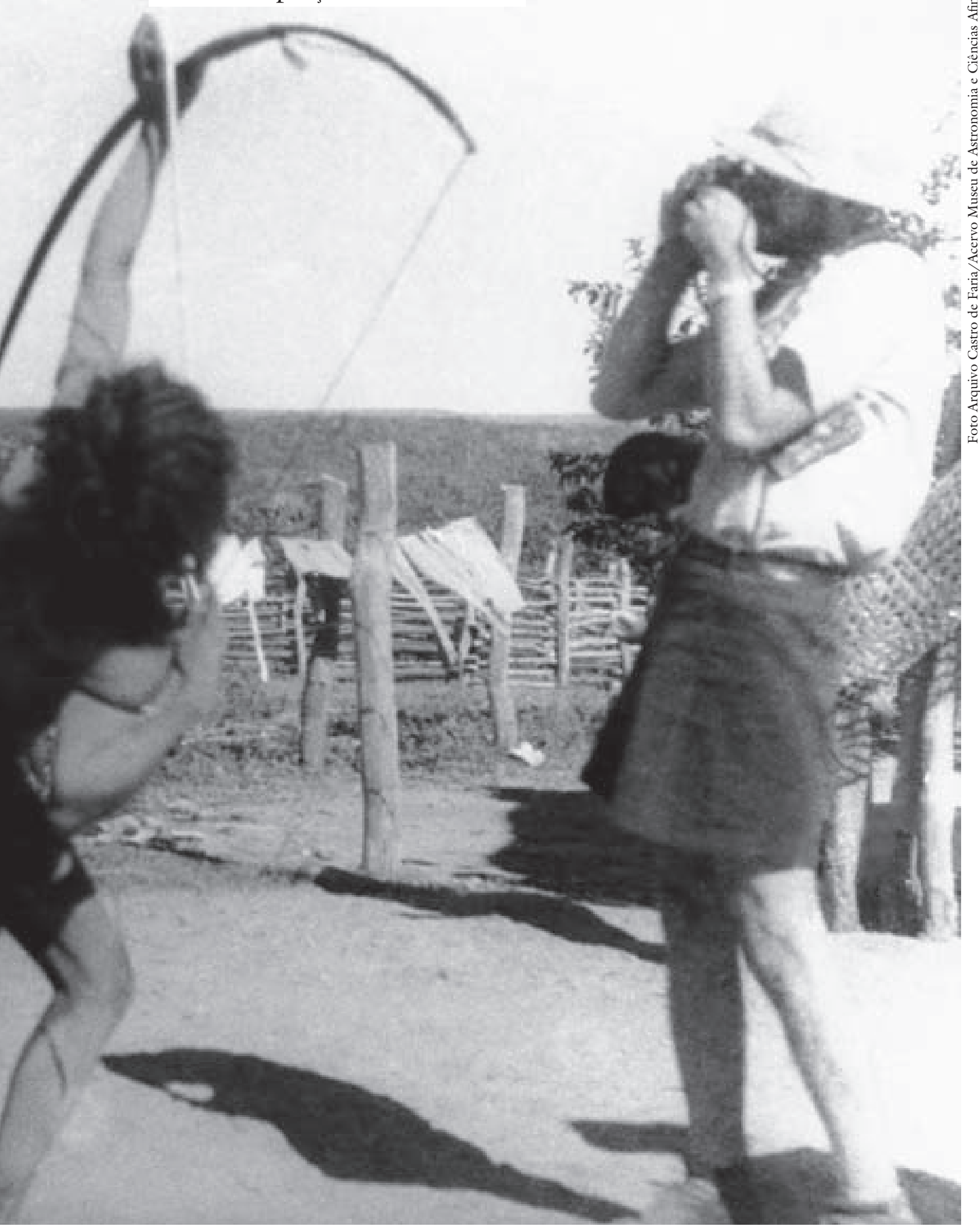


melhor os mecanismos de fabricação próprios a esses moluscos que vivem no interior da concha. Ele quer mostrar que a estrutura já está nas coisas aparentemente informes e aleatórias da diversidade individual (todas as ostras são semelhantes em sua organização corporal, mas nenhuma é igual à outra). Para ele, a etnologia pode ser comparada ao trabalho de Mendeleiev: pode-se compreender a totalidade das culturas humanas como tendo um lugar preciso numa classificação sistemática, uma espécie de tabela periódica dos elementos culturais. ${ }^{5} \mathrm{Em}$ longo prazo e com muita ambição, pode-se esperar chegar a compreender as sociedades - as formas e estruturas de nossas conchas - e classificá-las numa tabela progressiva, à maneira de Mendeleiev ou da física atual, cuja coerência requer a existência do bóson de Higgs, mesmo se este nunca foi observado.

O empreendimento é plausível com a condição de admitir que algumas possibilidades lógicas nunca foram realizadas e não podem sê-lo (ao menos no estado atual da evolução da humanidade, o que não é prejulgar o futuro), porque elas infringiriam imposições fundamentais que são da ordem dos parâmetros conceituais iniciais de que é dotada a humanidade. A meu ver, a valência diferencial dos sexos representa o parâmetro central, estruturador. Todo um conjunto de possibilidades no domínio do parentesco, das terminologias, da residência, da filiação e da aliança, da organização social e do jogo de poder, mesmo sendo fórmulas logicamente possíveis, são irrealizáveis neste instante de nossa própria história, porque implicariam uma forma de superioridade do gênero feminino sobre o masculino, o que iria contra a valência diferencial dos sexos. Em nossa tabela de Mendeleiev, algumas casas ficariam portanto vazias, certamente ainda por muito tempo.

A metáfora do molusco e da concha secretada abre uma pista extremamente fecunda, que obriga a associar estruturalismo e humanismo, não a dissociálos. Com efeito, parece que o jogo individual (de tal molusco, de tal pessoa), por evidente que seja, se molda nas estruturas das quais ele crê escapar.

La Lettre - Sobre a questão do naturalismo e da relação natureza-cultura, o pensamento de Lévi-Strauss variou ao longo da sua obra. Os debates sobre esse ponto evoluiram especialmente com as contribuições da etologia.

$F H$ - Sim. Realmente não há mais necessidade de estabelecer linhas de ruptura, de definir um ponto de corte. Para Lévi-Strauss, isso era fundamental porque ele fazia da proibição do incesto o ponto nodal em que de repente o homem entra na cultura pela necessidade do sentido. Precisava justificar a distinção entre um antes e um depois dessa passagem obrigatória, desse limiar a transpor. Creio que ele mesmo se deu conta de que, em realidade, a fronteira não era tão claramente marcada, e não estou certa de que sustentaria hoje o mesmo discurso da época em que escreveu As estruturas elementares do parentesco, isto é, antes da guerra. De minha parte, essas questões não estão no centro das minhas preocupações, mas tendo a pensar que não há, entre natureza e cultura, uma barreira assim tão nítida e manifesta exclusivamente na proibição do incesto. Trata-se 
mais, talvez, de uma espécie de zona-tampão ou de uma passagem bastante sinuosa e complexa. Além disso, é provavelmente uma passagem progressiva, cuja cronologia precisa é difícil reconstituir.

A etologia nos mostra, cada vez mais, sociedades animais capazes de aquisição de técnicas, de aprendizagem, de transmissão às gerações seguintes, e mesmo capazes de antecipação. Afetos que acreditávamos propriamente humanos podem ser identificados em espécies animais, assim como um certo senso da equidade ou um cálculo dos benefícios comparados do egoísmo e do altruísmo. Tudo isso faz vacilar a noção de uma fronteira nítida entre natureza e cultura.

Mas é verdade que há um antes e um depois. Antes as pessoas viviam em pequenas comunidades nas quais se estabeleciam as relações sexuais, provavelmente com um macho dominante que se reservava o acesso às parceiras femininas, antes de ser derrubado por outros ou antes de se criarem, sem que ele soubesse, relações clandestinas etc. Esse antes não era o social lévi-straussiano, ou, mais exatamente, era um outro tipo de social. Penso que a valência diferencial dos sexos já estava presente, porque ela é o produto de uma reflexão feita pelos humanos dos dois sexos, a partir da observação de um certo número de características biofisiológicas constantes que eles conhecem (o calor do corpo, o sangue que se apresenta sob diferentes formas, que não sai da mesma maneira do corpo das mulheres e do corpo dos homens, o fato de serem sempre as mulheres que procriam e de elas trazerem ao mundo crianças dos dois sexos). O questionamento sobre a diferença sexuada não pode ser datado com precisão. No entanto, a valência diferencial dos sexos preexistiu, ou pelo menos coexistiu com, à proibição do incesto. Foram outras necessidades, que não a criação do vínculo social, que fizeram aparecer a proibição do incesto, cuja emergência foi facilitada pela existência da valência diferencial dos sexos e pelo fato de os humanos se absterem de se reproduzir no interior do próprio grupo, buscando cônjuges em outros grupos. Com isso a passagem da natureza à cultura se dilui, tanto em suas manifestações e suas causas quanto no tempo e no espaço, e é inútil tentar situá-la.

La Lettre - A senhora pensa que Lévi-Strauss tinha a impressão de fazer uma viagem no tempo ao viajar no espaço?

$F H$ - Não penso que ele quisesse fazer uma obra de historiador. Ele faz um trabalho atemporal, isto é, não busca de modo algum datar. Como teríamos a pretensão de datar fatos que são fatos mentais? Formulamos hipóteses, verossímeis, que podem se adaptar à realidade que conhecemos e ao passado que descobrimos, mas não é mais que um roteiro. Lévi-Strauss extrai a lógica de uma evolução ocorrida numa história que ele não busca situar cronologicamente. Mas o olhar desviado da relação entre os sexos certamente o induziu a ver a proibição do incesto como um fato social isolado, que parecia se impor como o lugar de uma passagem da condição de obscuridade quase animal a uma condição iluminada do social regido pela lei. Se ele tivesse examinado outros aspectos da reflexão dos homens sobre seu universo biológico, sobre seu corpo etc., tal- 
vez não tivesse postulado dessa forma que há entre natureza e cultura uma linha de demarcação clara e que se deve a uma única causa.

\section{La Lettre - Qual é o lugar do corpo em Lévi-Strauss?}

$F H$ - Lévi-Strauss é um etnólogo de uma cultura enciclopédica. Se nos mitos aparece uma borboleta, um lêmure, um animal ou uma planta quaisquer, ele sabe tudo o que os índios dizem dessa borboleta, desse animal, dessa planta etc., mas também sabe tudo o que dizem os botânicos e os zoólogos. Assim, ele é capaz de utilizar esse conhecimento íntimo para compreender como os índios puderam, por um trabalho de reflexão sobre as cores das borboletas ou as capacidades da língua do tamanduá, por exemplo, criar seu universo mítico. Faz uma ligação entre o conhecimento científico e esses conhecimentos locais trazidos pelas etnociências que ele conhece muito bem, e relacionados a corpos, vegetais ou animais. Interessa-se pelos corpos, sobretudo na medida em que há uma representação mental das características desses corpos, que faz parte do universo dos índios. Essa representação mental lhes permite estabelecer categorias abstratas que servem de armação conceitual aos mitos. É um procedimento muito complexo. Mas a antropologia do corpo não era, em si mesma, o seu objeto, como se tornou o meu no meu ensino.

La Lettre - Que importância Lévi-Strauss dá à estrutura do cérebro?

$F H$ - Não se sabia grande coisa do funcionamento cerebral na época em que Lévi-Strauss escreveu suas grandes obras. Era o início dos computadores e do modelo informático do cérebro. Ele escreveu que o cérebro humano procede como um computador, num modo de codificação binário, e considerava que essa estrutura fundamental do funcionamento do cérebro, dada como herança desde o nascimento, influía sobre a criação de categorias dualistas. Via nisso uma capacidade universalmente compartilhada por toda a humanidade. De minha parte, atribuo esse traço à observação pelos humanos de algumas características naturais como o fato de haver apenas dois sexos.

Pensava-se na época que a criança nascia com a totalidade de sua organização sináptica. Sabe-se agora que fabricamos sinapses a vida inteira, o que permite ao cérebro, por exemplo, se recuperar mesmo após lesões graves. Sabe-se também que as aprendizagens precoces permitem criar circuitos que se consolidam pelo hábito. Portanto, é legítimo pensar que as opiniões correntes, segundo as quais, por exemplo, os homens seriam mais dotados para a matemática e as mulheres para a literatura, dependem muito da aprendizagem e de seus efeitos na organização do cérebro. Se as crianças compartilhassem o mesmo tipo de educação, é provável que essas desigualdades se apagassem. De fato, a infância é um período determinante para o desenvolvimento cerebral. Isso não se sabia na época em que Lévi-Strauss se referiu a uma organização cerebral constante e dada desde o nascimento.

La Lettre - Para concluir, o que lhe inspira o destino singular desse homem que deu à antropologia uma dimensão nova, um jovem de formação clássica que 
lecionou por dois anos num liceu e brutalmente se viu projetado num mundo desconhecido que ele se pôs a explorar com paixão?

$F H$ - Lévi-Strauss conheceu as desgraças do século - a guerra, a partida forçada aos Estados Unidos, a perseguição aos judeus etc. É também um homem que teve uma sorte excepcional e dela soube tirar um partido exemplar: teve a sorte de ser formado para uma profissão - foi um ótimo professor - e aproveitou a oportunidade que lhe era oferecida de partir para o Brasil. Ao mudar radicalmente de vida e de perspectiva ao mesmo tempo que permanecia fiel à sua vocação intelectual de início muito filosófica, ele soube não criar uma disciplina - que já existia antes dele -, mas dar-lhe uma solidez, uma realidade, uma verdade que antes não possuía, embora houvesse grandes antropólogos na França e na Europa. Lévi-Strauss realizou uma vida intelectual magnífica e soube teorizar uma disciplina, dando a ela seus títulos de nobreza.

Eu disse que ele teve sorte: teve sorte e coragem. Com sua bela inteligência, soube construir, com esses ingredientes, um destino excepcional.

Notas

1 Conceito que lancei no mercado.

2 Ver texto no Quadro 1.

3 Cf. <http://mediaplayer.archives.tsr.ch/personnalite-levistrauss/2.wmv>. Trata-se do programa "Personnalités de notre temps", 1965 (realizador: Y. Butler). Claude LéviStrauss responde a H. Stierling, Archives TSR.

4 Cf. igualmente Lévi-Strauss (1973, p.319), e a conclusão da aula inaugural no Collège de France (1960) (ibidem, p.44).

5 Ver o quadro Quadro 2.

Referências bibliográficas

FARIA, L. de C. Um outro olhar. Diário da expedição à Serra do Norte. Rio de Janeiro: Ouro Sobre Azul, 2001. (Edição inglesa: Another Look. A diary of the Serra do Norte expedition).

LÉVI-STRAUSS, C. Les trois humanismes. In: Anthropologie structurale deux. Paris: Plon, 1973. Question de parenté. L’Homme, n.154-155, 2000.

Françoise Héritier é professora honorária do Collège de France, foi titular da Cátedra de Estudos Comparativos das Sociedades Africanas de 1982 a 1998.

Publicado em Hors Série - La Lettre du Collège de France, Claude Lévi-Strauss - Centième anniversaire, Novembre 2008. Entrevista concedida a Marc Kirsch. Tradução de Paulo Neves. O original em francês - "Claude Lévi-Strauss vu par Françoise Héritier" - encontra-se à disposição do leitor no IEA-USP para eventual consulta.

Recebido em 16.7.2009 e aceito em 21.8.2009. 


\section{Quadro 1}

"Na savana escura, os fogos do acampamento brilham. Em volta do fogo, a única proteção contra o frio que desce é o frágil anteparo de folhas de palmeira e ramagens plantadas às pressas no chão do lado de onde se teme o vento ou a chuva. Junto aos cestos com os pobres objetos que constituem toda uma riqueza terrestre, deitados diretamente na terra que se estende ao redor, frequentada por outros grupos igualmente hostis e temerosos, os casais estão estreitamente enlaçados, cada indivíduo sendo para o outro o apoio, o reconforto, o único amparo contra as dificuldades cotidianas e a melancolia sonhadora que de vez em quando invade a alma Nambiquara. O visitante, que pela primeira vez acampa no mato com os índios, sente-se tomado de angústia e de piedade diante do espetáculo dessa humanidade tão desprotegida, como esmagada contra o solo de uma terra hostil por algum implacável cataclismo, nua, trêmula de frio junto aos fogos vacilantes. Cuidando para não ferir a mão, o braço, o torso, ele circula às cegas pelo matagal cujos reflexos se adivinham à claridade das fogueiras. Mas essa miséria é animada de cochichos e risos. Os casais se enlaçam como na nostalgia de uma unidade perdida, as carícias não se interrompem à passagem do estrangeiro. Em todos se percebe uma imensa gentileza, uma profunda despreocupação, uma ingênua e encantadora satisfação animal, e, reunindo esses sentimentos diversos, algo como a expressão mais comovente e mais verídica da ternura humana."

(C. Lévi-Strauss. Tristes tropiques. Paris: Plon, 1955, p.345)

\section{Quadro 2}

"O conjunto dos costumes de um povo é sempre marcado por um estilo; eles formam sistemas. Estou convencido de que esses sistemas não existem em número ilimitado e de que tanto as sociedades humanas como os indivíduos em seus jogos, em seus sonhos ou em seus delírios - nunca criam de forma absoluta, mas se limitam a escolher algumas combinações num repertório ideal que seria possível reconstituir. Fazendo o inventário de todos os costumes observados, de todos aqueles imaginados nos mitos, mas também evocados nos jogos das crianças e dos adultos, nos sonhos dos indivíduos sadios ou doentes e nas condutas psicopatológicas, conseguiríamos traçar uma espécie de tabela periódica como a dos elementos químicos, em que todos os costumes reais ou simplesmente possíveis apareceriam agrupados em famílias, e nos quais só teríamos de reconhecer aqueles que as sociedades efetivamente adotaram.”

(C. Lévi-Strauss. Tristes tropiques. Paris: Plon, 1955, p.205) 